\title{
A Rare Case of a Giant Cavernous Lymphangioma of the Chest Wall in a Child
}

\author{
Seydou Togo ${ }^{*}$, Moussa Abdoulaye Ouattara1, Ibrahim Boubacar Maiga1, Yunping Lu², \\ Donghui Jin², Ibrahim Sangaré1, Maiga Abdoul Aziz'1, Cheik Amed Sekou Touré1, \\ Ibrahim Coulibaly', Jaques Saye ${ }^{1}$, Cheik Sadibou', Sékou Koumaré ${ }^{3}$, Sadio Yéna1, \\ Djibril Sangaré 3 \\ ${ }^{1}$ Thoracic Surgery Department, Mali Hospital, Bamako, Mali \\ ${ }^{2} 24$ th Chinese Medical Team, Mali Hospital, Bamako, Mali \\ ${ }^{3}$ Surgery " $A$ " Department, Point G Hospital, Bamako, Mali \\ Email: "drseydoutg@yahoo.fr
}

Received 19 January 2016; accepted 22 February 2016; published 25 February 2016

Copyright (C) 2016 by authors and Scientific Research Publishing Inc.

This work is licensed under the Creative Commons Attribution International License (CC BY). http://creativecommons.org/licenses/by/4.0/

(c) (7) Open Access

\begin{abstract}
Cavernous lymphangioma of the chest wall is a very rare disease entity, and only a few cases have ever been documented in the literature. Cases of recurrent cavernous lymphangioma after surgical excision of a cystic lymphangioma on the same side of the chest wall are quite uncommon. We report a case of a 10-year-old girl, with a giant cavernous lymphangioma of the left lateral chest wall extending into the axilla, who had undergone surgical excision of a cystic lymphangioma 9 years earlier.
\end{abstract}

\section{Keywords}

Cavernous Lymphangioma, Chest Wall

\section{Introduction}

Cavernous lymphangiomas are a congenital malformations or abnormalities of the lymphatic system that results from failure of a primary lymphatic sac to establish drainage into the venous system. The basic pathologic process is the collection of lymphatic cisterns in the deep subcutaneous plane. These cisterns are separated from the normal network of lymph vessels, but they communicate with the superficial lymph vesicles through vertical, dilated lymph channels. They tend to grow but they also tend to recur if not resected completely. Lymphangiomas are known to occur in the neck, but also in the axilla and other sites such as the mediastinum, pelvis and

*Corresponding author.

How to cite this paper: Togo, S., Ouattara, M.A., Maiga, I.B., Lu, Y.P., Jin, D.H., Sangaré, I., Aziz, M.A., Touré, C.A.S., Coulibaly, I., Saye, J., Sadibou, C., Koumaré, S., Yéna, S. and Sangaré, D. (2016) A Rare Case of a Giant Cavernous Lymphangioma of the Chest Wall in a Child. Open Journal of Respiratory Diseases, 6, 1-6. http://dx.doi.org/10.4236/ojrd.2016.61001 
retroperitoneum [1]. Cavernous lymphangiomas are benign lesions that often present with anemia. The incidence of reporting of cavernous lymphangiomas appears to be increasing. Lymphangiomas account for $6 \%$ of small bowel tumours seen in children and they account for $4 \%$ of all vascular tumors and approximately $25 \%$ of all benign vascular tumors in children [2]. About $1 \%$ of all lymphangiomas are confined to the chest wall [3]. Largely asymptomatic, cavernous lymphangioma can present a diagnostic challenge often requiring lymphoscintigraphy, computed tomography (CT) and magnetic resonance imaging (MRI) to identify [4]. We present a rare patient with a huge cavernous lymphangioma in the chest wall, which underwent successful surgical management.

\section{Case Presentation}

A 10-year-old girl presented at our hospital with a bulging of the left lateral chest wall and left axilla. The mass in the left chest wall had 9 years history. Physical examination revealed a movable non-tender mass located in the left chest wall measuring $22.6 \mathrm{~cm}$ in diameter. On palpation the mass was fluctuant, it consisted of soft tumors. The mass extended from beneath the pectoralis major muscle to beneath the latissimus dorsi muscle and from the 10th intercostal space to the axilla (Figure 1). She reported no fever. Tuberculin test was negative. There were no other swellings elsewhere. The patient had undergone a successful surgical axillary excision of a $3 \mathrm{~cm}$ diameter cystic lymphangioma of the left chest wall under general anesthesia at the age of 16 months. At that time the tumor was misdiagnosed and has been managed for tuberculosis of axillary lymph node until the histological diagnosis was made. No others physical abnormalities have been detected at birth. Thereafter, she was regularly followed up and her postoperative course was uneventful until this recurrence. The tumor reappeared 3 month after surgery. When the mass was mobilized, the patient complained of mild pain. The patient underwent African traditional therapy for awhile without success. Traditional therapy is a psychological treatment and was found to be the last hope for the patients especially in a resource-poor country. It consists in treating the patients with plants or making sacrifices. Because of poverty, the family decided to keep the child at home and no diagnosis was made until the admission. Since then, the mass gradually increased in size. The previous operation area had direct communication with the newly developed lesion, and we noted old fibrotic scar in the area of the old cystic lymphangioma. The mass was evident on chest X-ray (Figure 2), while chest computed tomography (CT) revealed a homogeneous, low-attenuation mass with an internal hypoechoic pattern (Figure 3). The mass was extending from beneath the pectoralis major and latissimus dorsi muscles to the upper area of the clavicle without obviously invading the clavicle or the ribs. There was no intrathoracic or intra-abdominal extension. Doppler echography showed no blood flow. No significant findings were detected on blood tests, and serum tumor markers were negative. The patient was scheduled for operation of tumor removal. She was placed in a lateral position, as in the operation for axillary thoracotomy under general anesthesia. At

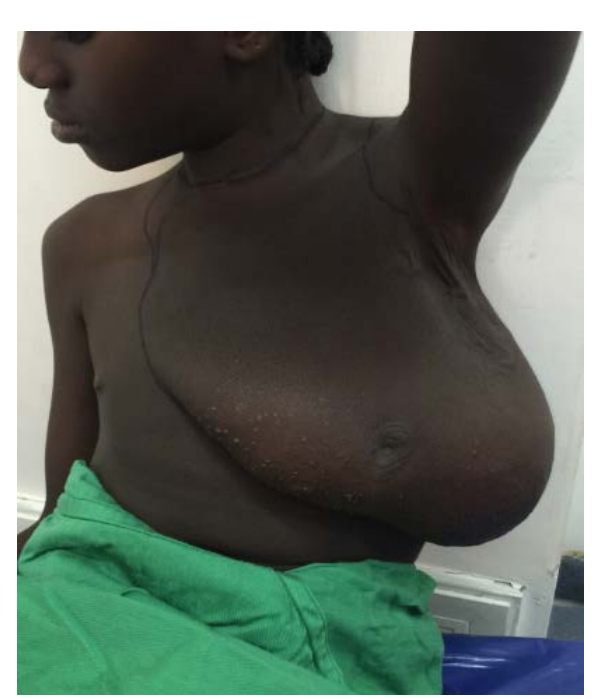

(a)

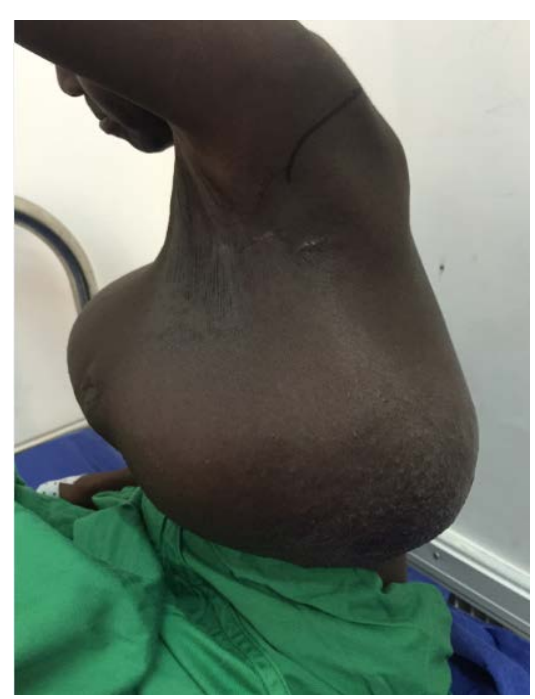

(b)

Figure 1. Image showing chest wall lymphangioma. (a) front vue; (b) lateral vue. 


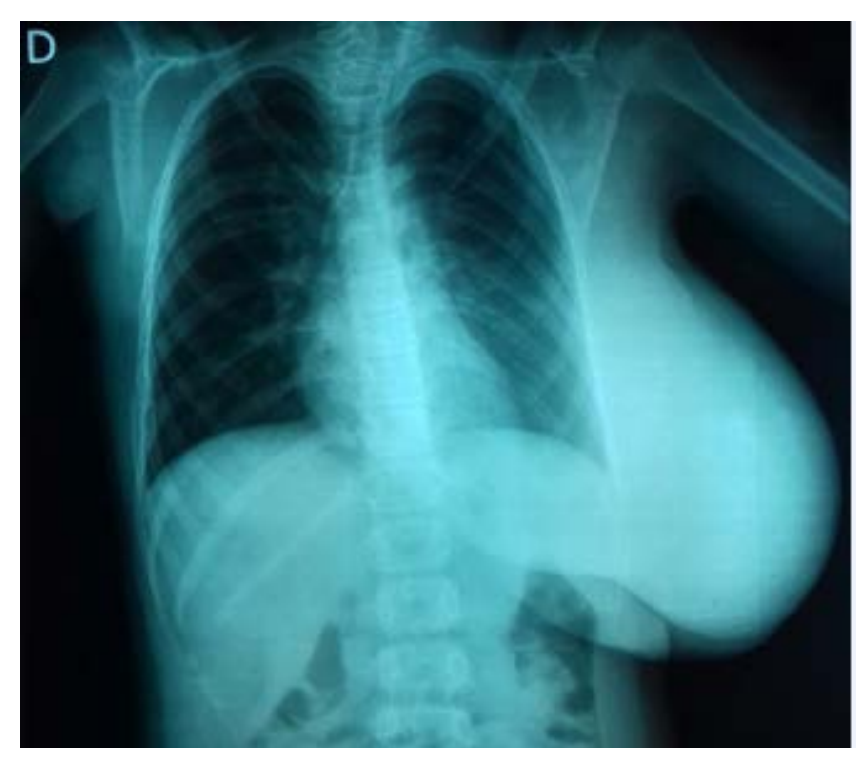

Figure 2. Chest radiography showing lateral mass in the chest wall.

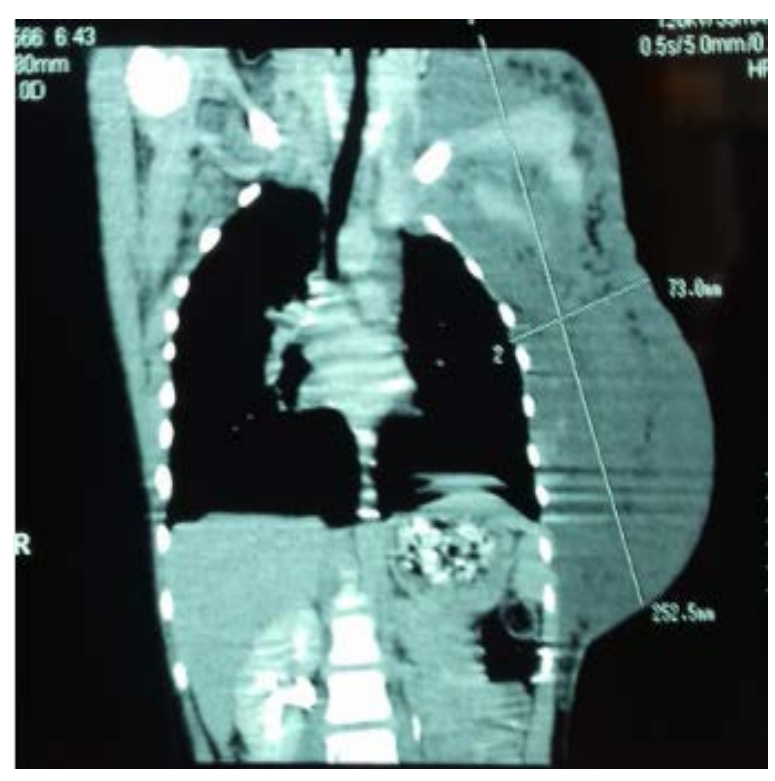

(a)

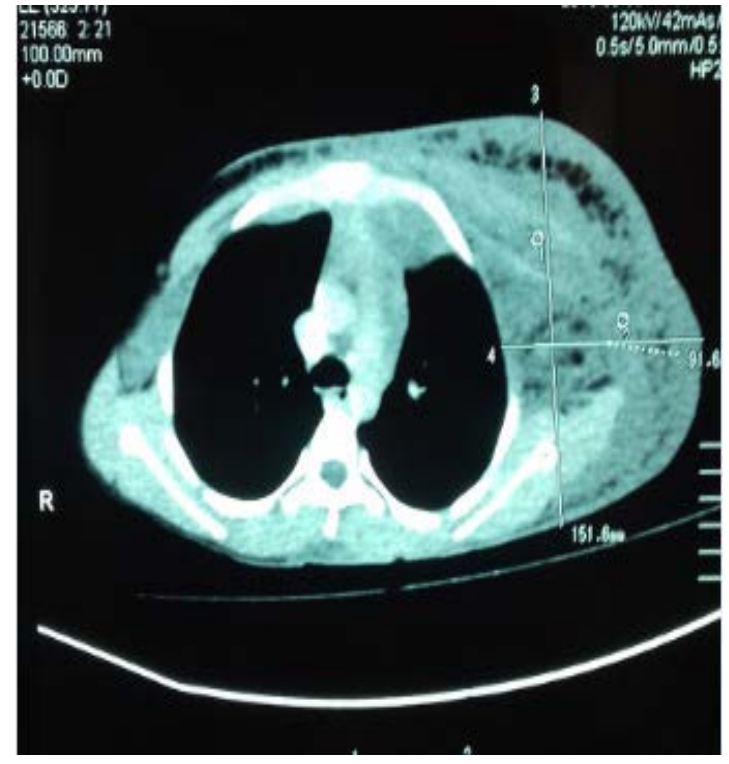

(b)

Figure 3. Chest CT scan: (a): soft tissue low-attenuation mass is evident in the chest wall; (b): mass with an internal hypoechoic pattern.

surgery, a skin incision was made to the surface of the mass which was filled with milky fluid and aspiration of $2600 \mathrm{ml}$ whitish fluid was made (Figure 4). We decided secondary an incision through the left axilla where the feeding vessels in the axilla were found. We performed a bloc ligation of the feeding vessels without scarifying the nerves (Figure 5). Numerous cavernous and dilated spaces in the subcutaneous tissues with flap skin were observed after aspiration. Complete excision of dark colored subcutaneous tissues with thick walls was made (Figure 6). Closure of the subcutaneous tissue and skin was performed over suction drain. The patient's postoperative condition was good, without complications. In proteomic analysis, the protein chip technology, surface-enhanced laser desorption/ionization-time of flight-mass spectrometry (SELDI-TOF-MS) and two- dimensional gel electrophoresis (2-D PAGE) was employed to examine the protein expression profiles of lymph. Major proteins identified in 2-D PAGE gels of lymph included, fibrinogen alpha- and beta-chains, immunoglobulin $\mathrm{G}(\mathrm{IgG})$ heavy chain, serotransferrin precursor, lactoferrin, and apolipoprotein A-1. Further histopathologic in- 


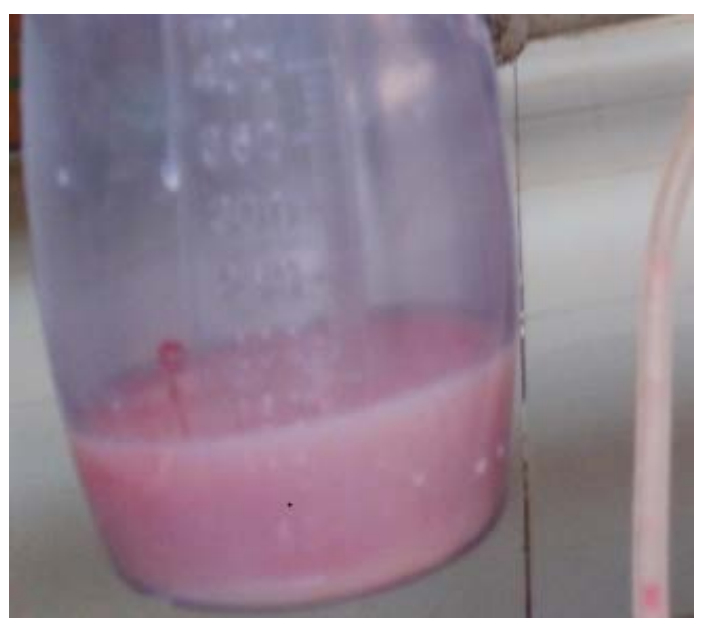

Figure 4. Aspirated milky fluid filled in the mass.
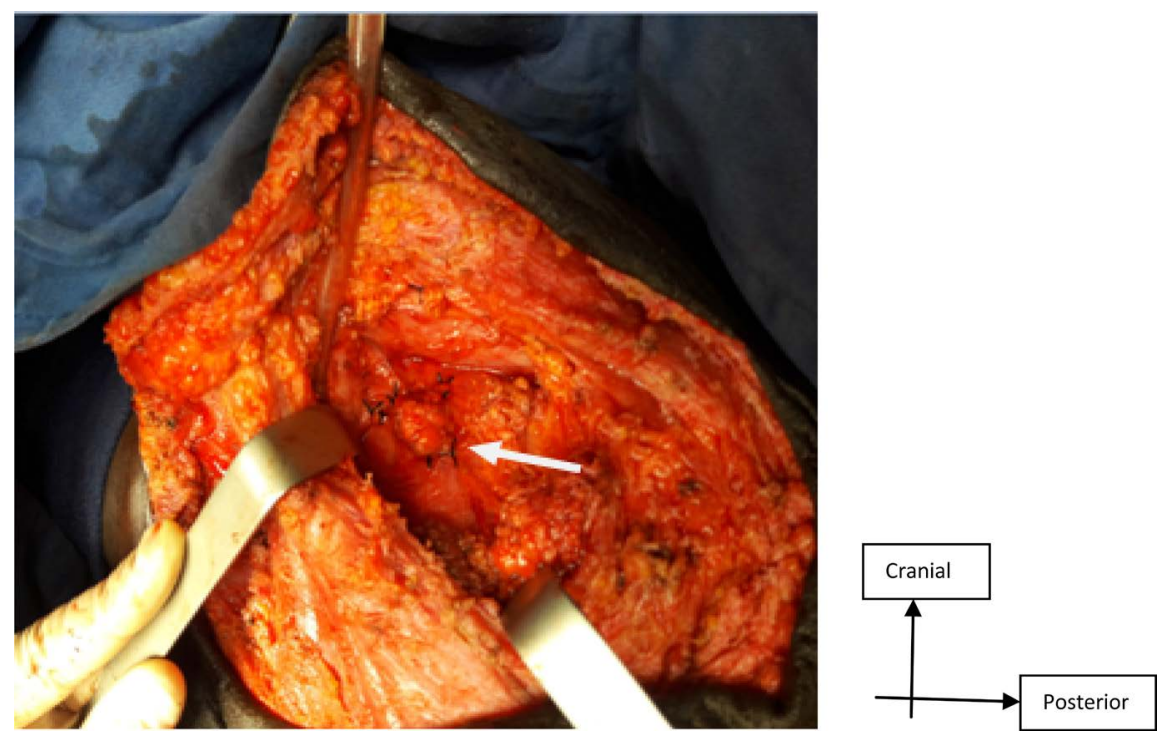

Figure 5. Incision through the left axilla with en bloc ligation of the feeding vessels.

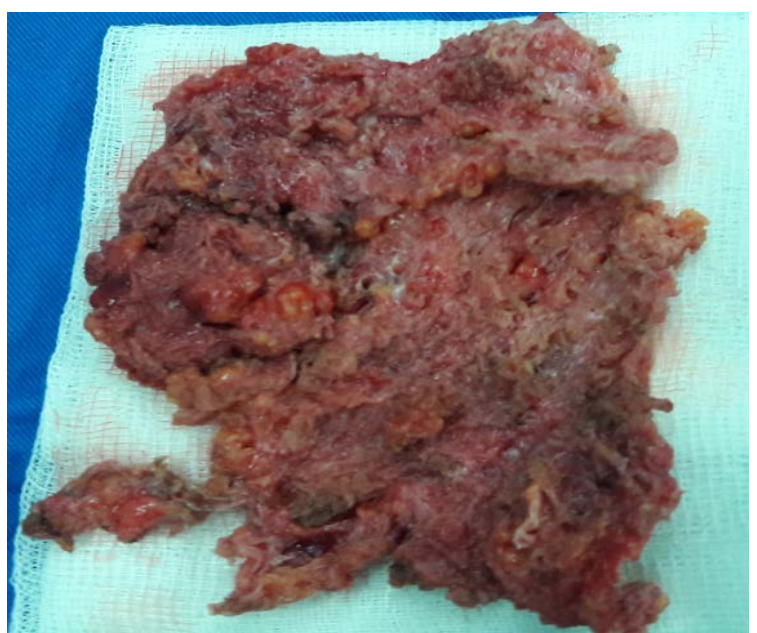

Figure 6. Dissected dark colored subcutaneous tissues with thick walls. 
vestigation ascertained the presence of an abnormal proliferation of enlarged vascular channels lined with endothelium. Positive staining by D2-40 of endothelial cells affirmed that these channels were indeed lymphatic proliferations. The final histologic diagnosis was cavernous lymphangioma of the chest wall. Her postoperative course was uneventful without any recurrence. Chest X-ray performed 3 months after surgery was normal (Figure 7). Ethical committee and patient's parents have given informed consent to publication. The patient is invited for a yearly regular visit.

\section{Discussion}

Lymphangioma appear as a swelling tumor in the head, neck, or axilla [4] [5]. About 1\% of all lymphangiomas are confined to the chest wall [4] [5]. Hancock et al. [6] reported the distribution of lymphangiomas to be cervical $(31.4 \%)$, craniofacial $(18.9 \%)$, truncal $(9.2 \%)$ and cervicoaxillothoracic $(4.9 \%)$. Its embryologic origin is the aberrant proliferation or outgrowth of tissues derived from the primitive jugular sac. The overwhelming majority arises during fetal development and childhood but there have been rare reported cases of such structures being unveiled later in life [7]. The most widely accepted classification includes: a) cystic lymphangioma; b) cavernous lymphangioma and c) lymphangioma simplex [5]. Cystic formation is induced when primary lymphatic spaces fail to join the central system. The lack of communication between a lymphatic sac and the venous system produces a cystic lymphangioma [8]. The patient underwent surgery for cystic lymphangioma of the chest wall in the neonatal period and the mass recur with a cavernous presentation. Cavernous lymphangioma of the chest wall is rare with only few cases reported [9]. These tumors of lymphatic origin tend to grow, but they also tend to recur if not resected completely, as is the case in our patient. However, as noted above, cavernous lymphangioma rarely presents as a chest wall tumor. Cavernous lymphangioma is generally considered a benign mass occurring in the newborn and small child. 90\% appear by the end of the second year of life [10]. The tumor usually presents as a swollen bulge underneath the skin of the patient. On chest CT, the tumor usually appears as a homogeneous, low-attenuation mass, similar in appearance to that of water, but may show a higher attenuation or be comprised of a combination of fluid, solid tissue, and fat [11]. In this case chest CT was performed and has given precise evaluation of the tumor extent. MRI is helpful in the diagnosis of lymphangioma, which has heterogeneous signal intensity on T1-weighted images and high signal intensity on T2-weighted images, reflecting its fluid content [12]. At the time of admission, MRI was not available in our country. Surgical resection is recommended principally. In general, since in many cases there is lymphatic tissue showing cavernous structure in the surroundings of the cystic lymphangioma, it is important to perform complete resection including the circumferential tissues in order to prevent recurrence. Authors reported that recurrence after excision occurred when the surgical resection was performed incompletely and recurrence often occurred within 3 months after excision [13] [14]. That was similar in our case with the recurrence observed 3 month after the cystic lymphan-

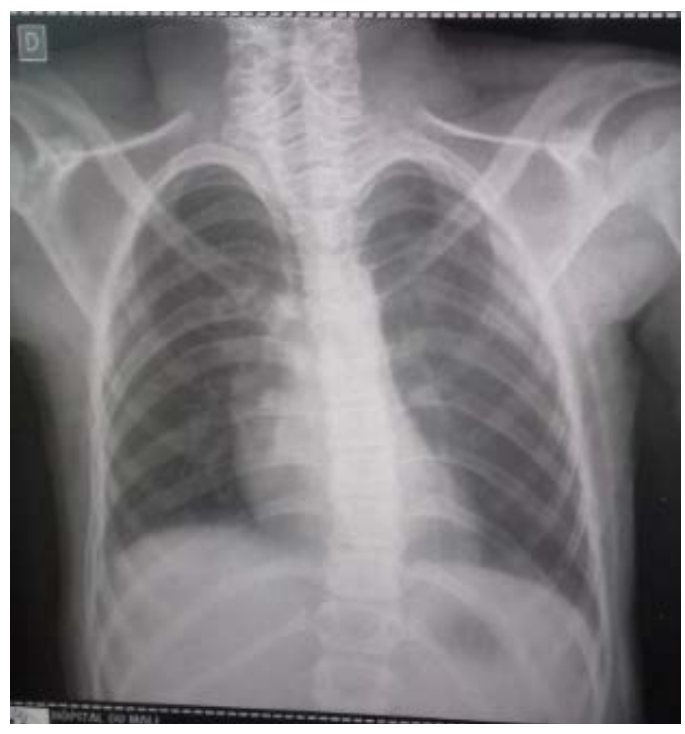

Figure 7. Postoperative chest X-ray. 
gioma excision. Since an exceptional recurrence appeared 7 years after excision [14], long-term follow-up is necessary. Cavernous lymphangioma detection in the early stage could avoid an increase of tumor volume, infection, anemia, vision problems, dysarthria or cardiac complications in children. Other types of adjuvant treatment have been proposed, such as radiotherapy, injection of sclerosing agents via $100 \%$ ethanol or OKT-432, but they are controversial [15] [16]. Because of resource-poor situation in our areas, such adjuvant treatment is not available. Surgical option is the only end goal in our context and it has been performed with success in this case. Reports of malignant alteration are unfounded. The patient we presented is a rare case of cavernous lymphangioma in the chest wall that was treated surgically. She underwent surgical removal of a cystic lymphangioma of the chest wall in the neonatal period but presented with a cavernous lymphangioma 9 years after the operation. We performed a radical excision of the lesion. When the lesion has been completely excised, it is thought that the prognosis is good.

\section{Conclusion}

Lymphangiomas of the thoracic wall are extremely rare lesions. This tumor should be considered during the evaluation of chest wall masses. MRI or CT scan with precise evaluation of the tumor extent may provide a clue for the correct diagnosis. Early diagnosis and complete surgical excision as the most effective treatment modality is of utmost importance to avoid morbidity and recurrence of such lesions.

\section{References}

[1] Alqahtani, A., Nguyen, L.T., Flageole, H., Shaw, K. and Laberge, J.-M. (1999) 25 Years' Experience with Lymphangiomas in Children. Journal of Pediatric Surgery, 34, 1164-1168. http://dx.doi.org/10.1016/S0022-3468(99)90590-0

[2] Fonkalsrud, E.W. (1994) Congenital Malformations of the Lymphatic System. Seminars in Pediatric Surgery, 3, 62-69.

[3] Okazaki, T., Iwatani, S., Yanai, T., et al. (2007) Treatment of Lymphangioma in Children: Our Experience of 128 Cases. Journal of Pediatric Surgery, 42, 386-389. http://dx.doi.org/10.1016/j.jpedsurg.2006.10.012

[4] Yokoigawa, N., Okuno, M. and Kwon, A.H. (2014) Cystic Lymphangioma of the Chest Wall: A Case Report. Case Reports in Gastroenterology, 8, 393-397. http://dx.doi.org/10.1159/000370030

[5] Kennedy, T.L., Whitaker, M., Pellitteri, P. and Wood, W.E. (2001) Cystic Hygroma/Lymphangioma: A Rational Approach to Management. The Laryngoscope, 111, 1929-1937. http://dx.doi.org/10.1097/00005537-200111000-00011

[6] Hancock, B.J., St-Vil, D., Luks, F.I., Di Lorenzo, M. and Blanchard, H. (1992) Complications of Lymphangiomas in Children. Journal of Pediatric Surgery, 27, 220-224. http://dx.doi.org/10.1016/0022-3468(92)90316-Y

[7] Oshikiri, T., Morikawa, T., Jinushi, E., Kawakami, Y. and Katoh, H. (2001) Five Cases of Lymphangioma of the Mediastinum in Adults. Annals of Thoraacic and Cardiovascular Surgery, 7, 103-105.

[8] Fonnkaisurd, E.W. (1986) Disorders of the Lymphatic System. In: Welch, K.J., Randolph, J.G., Ravitch, M.M., O’Neill Jr., J.A. and Rowe, M.I., Eds., Pediatric Surgery, Vol. 2, Year Book Medical Publishers, Chicago, 1506.

[9] Krainick-Strobel, U., Kraimer, B. and Walz-Mattmuller, R. (2006) Massive Cavernous Lymphangioma of the Breast and Thoracic Wall: Case Report and Literature Review. Lymphology, 39, 147-151.

[10] Chung, S.Y., Oh, K.K. and Kim, D.J. (2003) Mammographic and Sonographic Findings of a Breast Cystic Lymphangioma. Journal of Ultrasound in Medicine, 22, 307-309.

[11] Jeung, M.Y., Gasser, B., Gangi, A., et al. (2002) Imaging of Cystic Masses of the Mediastinum. Radiographics, 22, S79-S93. http://dx.doi.org/10.1148/radiographics.22.suppl 1.g02oc09s79

[12] Shaffer, K., Rosedo-de-Christenson, M.L., Patz Jr., E.F., Young, S. and Farver, C.F. (1994) Thoracic Lymphangioma in Adults: CT and MR Imaging Features. American Journal of Roentgenology, 162, 283-289. http://dx.doi.org/10.2214/ajr.162.2.8310910

[13] Ward, P.H., Harris, P.F. and Downey, W. (1970) Surgical Approach to Cystic Hygroma of the Neck. Archives of Otolaryngology, 91, 508-514. http://dx.doi.org/10.1001/archotol.1970.00770040738003

[14] Flanagan, B.P. and Helwig, E.B. (1977) Cutaneous Lymphangioma. Archives of Dermatology, 113, 24-30. http://dx.doi.org/10.1001/archderm.1977.01640010026002

[15] Ninh, T.N. and Ninh, T.X. (1974) Cystic Hygroma in Children: A Report of 126 Cases. Journal of Pediatric Surgery, 9, 191-195. http://dx.doi.org/10.1016/S0022-3468(74)80120-X

[16] Stringel, G. (1993) Hemangiomas and Lymphangiomas. In: Ashcroft, K.W. and Haldor, T.M., Eds., Pediatric Surgery, Saunders, Philadelphia, 814-816. 